\title{
Static calculations of the pipeline under sanitation by means of "pipe-in-pipe" method
}

\author{
Oleg Primin, Sergey Zotkin*, and Grigory Gromov \\ Moscow State University of Civil Engineering, Yaroslavskoe shosse, 26, Moscow, 129337, Russia
}

\begin{abstract}
In recent years, methods of trenchless pipe reconstruction have become widely used in Russia. Once the polymer pipe pulled into the existing pipeline, the necessity of filling the intertube space with a mortar is solved. Due to the lack of clear recommendations on the implementation of the filling, builders often perform these works by trial and error. This requires special research. The article deals with an analysis of standards in this area, There is an example of a static strength calculation.
\end{abstract}

\section{Introduction}

In recent years, operative solutions of the problems associated with repairs and construction of pipeline networks are carried out mainly with the help of trenchless technologies of sanitation and pipeline laying, [1,2,3].

Nowadays foreign and domestic practice has more than twenty basic methods of trenchless pipe restoration. Among them the method of dragging new pipes into the worn out pipelines - the pipe-in-pipe method- is the most widely used, [4,5], Figure 1.

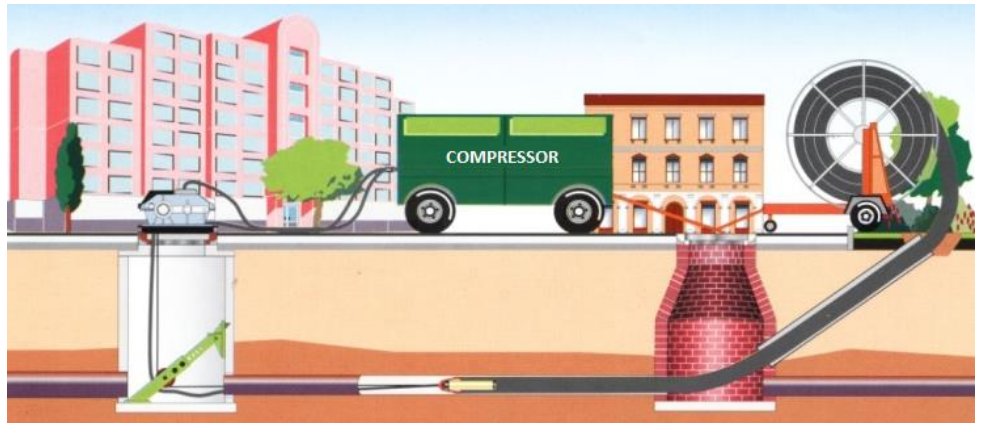

Fig. 1. Dragging a round polyethylene pipe from a reel into an old pipeline.

This method allows the reconstruction of pipelines in the shortest time and does not require a large amount of excavation. The merits of the method include the fact that the bearing capacity of the pipeline is completely restored, since the polymer pipe fulfills all the functions assigned to it, including strength ones.

\footnotetext{
* Corresponding author: zotkinsp@mgsu.ru
} 
When this method is implemented, it is very important to ensure the reliability and strength of the two-layer structures for the justification of the need for intertube space filling and static calculations.

\section{Materials and methods}

An analysis of domestic regulatory documents on filling the intertube space during the sanitation of pipelines pointed at the presence of gaps in this issue.

The building rule 31.13330.2012 [6] it is indicates:

11.51. Pipeline crossings under railways of I, II and III categories of general network, as well as under the roads of I and II categories should be performed in cases, and as a rule, a closed method of production should be provided. When preparing a justification it's allowed to lay pipelines in tunnels. There are no instructions on carrying out a filling.

The building rule 32.13330.2012 [7] indicates:

6.7.4. To maintain the necessary slop when laying a gravity pipeline through into a case, appropriate footings with guiding structures should be provided;

6.7.6 In some cases, once pulled the pipes, it is allowed to fill in the space between the pipes and the case with cement mortar;

6.7.7. The thickness of the walls of the steel case should be determined on the basis of the calculation taking into account the depth, and for the cases laid by means of puncture or punching method, the necessary effort developed by the jacks should be taken into account.

The buildings codes and rules 3.05.04 [8] indicate:

7.4. Pipelines laid on crossings through railways and highways of I and II categories are subject to preliminary testing after laying the working pipeline in a case (casing) until the intertube space of the shell cavity is filled in and before the working and receiving trenches of the passage are filled in.

The departmental document - "Recommendations for filling in the intertube space during the sanitation of pipeline by method of relining and when laying pipelines in cases" [9] indicates:

The filling of intertube gaps with hardening mortars and loose materials is carried out in order to fill the voids in the pipeline construction, ensuring the joint functioning of the pipe and the casing with the surrounding soil.

The injection of solutions improves the static work, reduces the deformation of the pipeline, ensures an increase in the water resistance of structures and, as a result, increases the durability of structures.

The Moscow building codes TSN 40-303-2003 [10] and the typical projects for the construction of crossings under roads provide recommendations as follows: it is necessary to pour concrete mortar M-200 into the gaps between the inner surface of the case (the existing pipeline) and the outer surface of the dragged pipe.

It is not specified how and why to cement the intertube space, what plasticity, fluidity the solution should have, what length the pipeline section for "filling" should have ,etc. Because of the lack of clear recommendations on the implementation of the "filling" of pipelines, as well as the lack of static calculations, builders often perform these works by trial and error.

It often results in deformation of pipes, formation of air bags and in-tube gaps, damaged strength of pipelines and their tightness deterioration which supposes material and environmental damage.

In general, the analysis of the available domestic regulatory documents put on display the lack of clear indications of the need for filling of the intertube space during the reconstruction of pipelines and when laying them in cases, as well as the requirements for 
filling mortars. This requires special research and justification of the need to fill in the intertube space.

Foreign regulatory documents contain more information on the problem of filling and the need for static calculations.

The German document "Instruction DWA-A 143-2 "Statistical calculations for the restoration of sewage pipelines and channels using the pipe-in-pipe technology and using prefabricated elements "[11] states:

The purpose of filling (in cases) is:

- to ensure the required positioning of the pipeline in the case,

- to provide an anticorrosive protection of steel and cast iron pipelines,

- to increase the effect of cathodic corrosion protection.

Foreign normative documents pay special attention to static calculations on the two-pipe structure strength, which, along with technical and economic comparison of the pipeline reconstruction options, determine the necessity of filling in the intertube space.

It is noted in the recommendations [12] that because of the hydrostatic pressure during the filling of the intertube space (the mounting stage), up to the complete hardening of the mortar, loads act upon the new and old pipe, which can lead to their destruction or loss of stability. Therefore, the stability of the new pipe with respect to the loads that arise when filling, must be confirmed by static calculation. [10]:

The degree of load is determined, first of all, by the influence of the following factors

- the new tube geometry,

- the fresh mortar density,

- the filling height or filling pressure,

- the range of filling material temperature

The ability of a new pipe to withstand loads is determined by the wall thickness, the properties of the filler and the structural material: stiffness and strength.

The solution of the problem of determining the loads values when filling in the intertube space with building mortars pumped into allows, taking into account the strength characteristics and geometric dimensions of the polymer pipes to be dragged, to reveal their ability to resist all kinds of loads.

At the same time, the absence of deformation should be guaranteed while ensuring the bearing capacity.

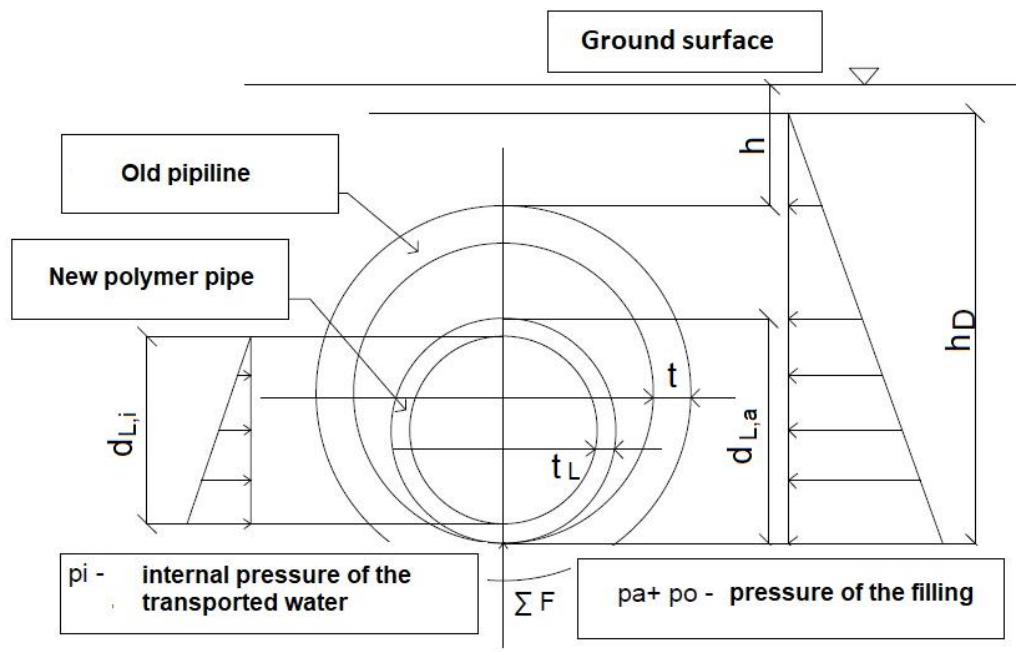

Fig. 2. Loads acting on the polymer pipe when filling the intertube space. 
Figure 2 shows how, when filling the intertube space with a mortar at once, four types of load are acting on the polymer tube:

1. The own weight $G_{L}=\gamma_{L} \cdot t_{L}$ of the walls of the polymer pipe along the circumference;

2. External pressure $p_{a}=\gamma_{D} \cdot d_{L, a}$ on the filler side;

3. The load on the outer surface of the pipe $p_{0}=\gamma_{D}\left(h_{D}-d_{L, a}\right)$ of the filler;

4. The internal pressure of the transported water $p_{i}=\gamma_{w} \cdot d_{L, i}$

When placing the polymer pipe on the tray, the following condition must be fulfilled [10]:

$$
\sum F=F_{G}+F_{W}-F_{D}=\gamma_{L} \cdot t_{L} \cdot 2 r_{L} \cdot \pi+\left(\gamma_{W} \cdot d_{L, i}^{2}-\gamma_{D} \cdot d_{L, a}^{2}\right) \cdot \frac{\pi}{4}>0
$$

here $d_{L, a}$ and $d_{L, i}$ are respectively the outer and inner diameters of the polymer tube,

$\gamma_{L}, \gamma_{W}, \gamma_{D}$-are correspondingly the specific weight of the polymer pipe, of ground water, and of the filler,

$p_{a}$ - is the groundwater pressure, $\mathrm{kN} / \mathrm{m}^{2}$,

$p_{0}$ - is the load on the outer surface of the pipe, $\mathrm{kN} / \mathrm{m}^{2}$,

$p_{i}$ - is the internal pressure of transported water, $\mathrm{kN} / \mathrm{m}^{2}$,

$G_{L}$ - is the load caused by the own weight of the pipe wall, $\mathrm{kN} / \mathrm{m}^{2}$,

$h_{d}$ - is the distance between the ground level and the pipeline sheath, $\mathrm{m}$,

$F_{G}$ - is the load caused by the own weight of the polymer pipe, $\mathrm{kN} / \mathrm{m}$,

$F_{W}$ - is the load that occurs when the pipeline is filled with water, $\mathrm{kN} / \mathrm{m}$,

$F_{D}$ - is the load caused by the weight of the filler, $\mathrm{kN} / \mathrm{m}$,

$t_{L}$ - is the wall thickness of the polymer pipe,m,

$r_{L}$ - is the average radius of the section of the polymer pipe, $m$,

When $\sum \mathrm{F}<0$, a floating towards the top of the pipe occurs.

As a result of superposition of internal stresses caused by the acting loads, stresses arise

[7], which can be determined by using equations (2-7):

$$
\sigma_{i, d}=\frac{\sum N_{d}}{A}+\alpha_{k, i} \cdot \frac{M_{W d}}{W_{i}},
$$

where $\sigma_{i, d}$ is the stress on the inner surface of the polymer pipe, $\mathrm{N} / \mathrm{mm}^{2}$,

$N_{d}$ - is the force determined by the presence of water, $\mathrm{kN} / \mathrm{m}$,

$A$ - is the cross-sectional area of the wall of the polymer pipe, $\mathrm{mm}^{2}$,

$M_{W d}$ - is the bending moment determined by the presence of water, $\mathrm{kNm} / \mathrm{m}$,

$W_{i}$ - is the moment of the polymer pipe wall resistance, $\mathrm{mm}^{3}$.

$$
M_{w d}=\gamma_{F} \cdot m_{w} \cdot \gamma_{w} \cdot r_{L}^{3}
$$

where $\gamma_{F}, \gamma_{w}$ are load resistance coefficients,

$m_{w}$ - is the bending moment coefficient, determined by the transported water pressure.

$\sigma a, d$ - is the pressure of the polymer pipe outer surface, $\mathrm{N} / \mathrm{mm}^{2}$,

$$
\sigma_{a, d}=\frac{\sum N_{d}}{A}-\alpha_{k, a} \cdot \frac{M_{d}}{W_{i}},
$$

where $M_{d}$ - is the bending moment determined by the filler material, $\mathrm{kNm} / \mathrm{m}$, $N_{d}$ - is the force determined by the filler material, $\mathrm{kN} / \mathrm{m}$,

$$
M_{d}=\gamma_{F} \cdot m_{d} \cdot \gamma_{d} \cdot r_{L}^{3}
$$

where $m_{d}$ - is the bending moment coefficient determined by the filler pressure, 
$\alpha_{k i}$ and $\alpha_{k a}$ - are the correction factors, determined by the formulas:

$$
\begin{aligned}
& \alpha_{k, i}=1+\frac{1}{3} \cdot \frac{t_{L}}{r_{L}}, \\
& \alpha_{k, a}=1-\frac{1}{3} \cdot \frac{t_{L}}{r_{L}},
\end{aligned}
$$

where $t_{L}$ - is the thickness of the polymer pipe wall, $\mathrm{mm}$,

$r_{L}-$ is the average radius of the polymer pipe section, $\mathrm{mm}$,

The new polymer pipe has the necessary load-bearing capacity under the following conditions:

$$
\frac{\max \sigma_{i, d}}{\sigma_{b Z, d}} \leq 1
$$

for longitudinal loads, (tensile stress), where $\sigma_{b Z, d}$ is the bending strength of the polymer pipe, $\mathrm{N} / \mathrm{mm}^{2}$,

$$
\frac{\max \sigma_{a, d}}{\sigma_{D, d}} \leq 1,
$$

where $\sigma_{D, d}$ is the compressive strength of the polymer pipe, $\mathrm{N} / \mathrm{mm}^{2}$.

Below are the results of a static calculation for pipeline sanitation by the "pipe-in-pipe" method with and without filling. The calculations were carried out by using a German program based on finite elements method calculation (Fig. 3) - methodology DWA-A 143-2 [11].
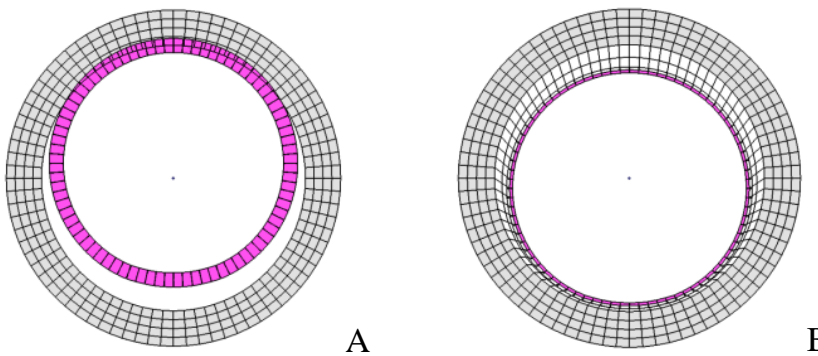

Fig. 3. A is a new unfilled polyethylene pipe, B is a filled polyethylene pipe.

In the calculation example, during the sanitation of an old pipeline, an old reinforced concrete pipe DN900 was used.

In the calculations, the following wall thicknesses of the new pipe were studied [13]:

- the new pipe PE 100, unfilled with SDR equal to 17 and the wall thickness equal to $48.2 \mathrm{~mm}$;

- the new PE 100 pipe, filled with SDR equal to 41 and the wall thickness equal to 20.0 $\mathrm{mm}$.

Compressive strength (predicted value) $\sigma_{D, L, k}=14 \mathrm{~N} / \mathrm{mm}^{2}$

Bending tensile strength (predicted value) $\sigma_{b Z, d}=14 \mathrm{~N} / \mathrm{mm}^{2}$ 


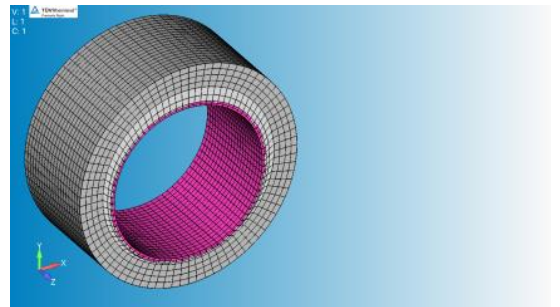

a) The new pipe da $820 \mathrm{~mm}$, filled, SDR 41
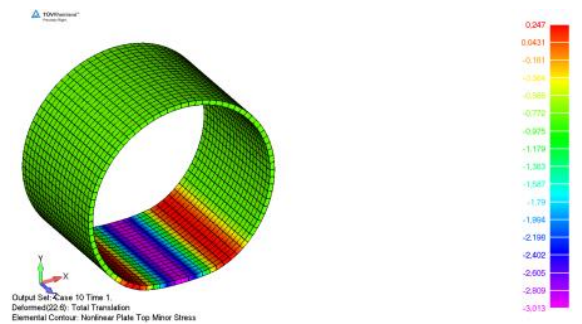

c) Second main stress (MPa) under the action of $\gamma_{F}$-aliquoted operational loads
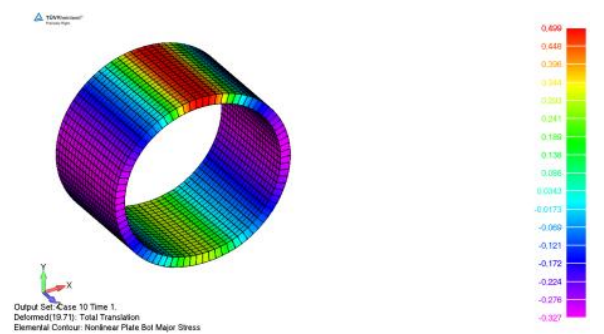

e) The first main stress (MPa) under the action of $\gamma_{F}$-aliquoted operational loads
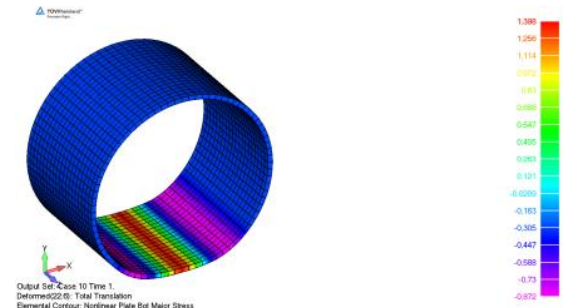

b) The first main stress (MPa) under the action of $\gamma_{F}$-aliquoted operational loads

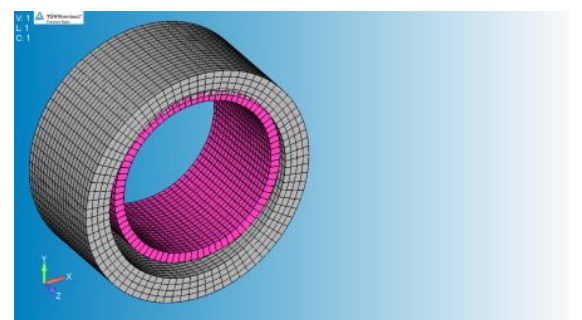

d) The sampled model of an unfilled new pipe
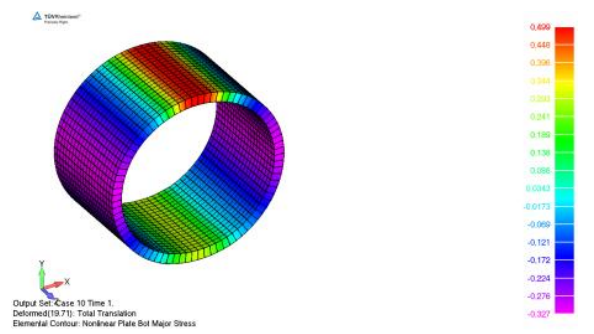

f) The second main stress (MPa) under the action of $\gamma_{F}$-aliquoted operational loads

Fig. 4. The sampled model of a new pipe

The new filled pipe $d_{a} 820 \mathrm{~mm}, \mathrm{SDR} 41$ is shown in Figure 4-a.

From Fig. 4-b (printout from the computer) it follows that the operational loads correspond to the maximum value of longitudinal stress of the new pipe: $\max . \sigma_{i, d}=1,40$ $\mathrm{MPa}$. Then the resistance to longitudinal loads is: $1,40 / 14=0,10$, which is $\leq 1.0$.

It follows from Fig. 4-c that the maximum value of compressive stress of the new pipe corresponds to operational loads proportional to $\gamma_{F}$ : $\max . \sigma_{D, d}=-3,01 \mathrm{MPa}$.

Then the stability of the new pipe with respect to the loads determined by the compression stress is $3,01 / 14=0,22 \leq 1,0$.

The new unfilled pipe $d_{a} 820 \mathrm{~mm}$, SDR 17, [11] is shown in Figure 4-d.

An illustration of the calculations performed on a computer is shown in Figures 4-e and 4-f.

It follows from Fig. 4-e that the maximum value of the longitudinal stress of a new pipe corresponds to the $\gamma_{F}$-aliquoted operational loads: $\max . \sigma_{i, d}=0,50 \mathrm{MPa}$.

Then the resistance to longitudinal loads is $0,50 / 14=0,04$, which is $\leq 1.0$.

It follows from Fig. 4-f that the compressive stress maximum load value of the new pipe corresponds to operational loads proportional to $\gamma_{F}$ : $\max . \sigma_{i, d}=-1.03 \mathrm{MPa}$.

Then the new pipe resistance to the loads caused by the compression stress is $1,03 / 14$ $=0,07$ that is $\leq 1.0$. 
Calculations have shown that under the action of $\gamma_{F^{-}}$aliqouted operating loads, the strength limit of the new pipe material is not reached.

Static calculations showed:

1. In case of long-term loads, the unfilled system requires a wall thickness more than twice as thick (SDR $17 \rightarrow$ SDR 41) in order to meet the requirements for resistance to acting stresses, deformation strength and stability.

2. If the system is not filled, then the new pipe does not have a "support", it can be deformed and in the extreme case it is punched in the tray. That deals with the problem of static stability, which can very quickly lead to an emergency situation.

\section{Results}

1. The decision about the feasibility of filling should be made on the basis of static calculations which consist on checking the bearing capacity of the new pipeline during the filling period.

2. The filling of the intertube space with the implementation of the trenchless technology of pulling the polymeric pipeline into the old pipeline helps to prevent:

- the appearance of negative supports on the walls of the old pipeline or random rigid objects inside it;

- increased stresses on the wall of the old (obsolete) pipeline;

- the "waviness" of the polymer pipeline within the old one;

- possibilities of damaging the stability of joints between the old pipeline material and polymer pipes near the reinforcement;

- deformation of the pipeline and increase the waterproofness of structures and, as a result, increase the durability of structures.

- changes in the position of the pipe caused by temperature changes, both inside the pipe and outside

- ground infiltration into the intertube space

- gas formation in the intertube space

- transport of groundwater in the intertube space.

3. When carrying out planned works related to the justification of the need to fill the intertube space during the sanitation of old pipelines after pulling in them new polymer pipes, it is necessary to take into account:

- state of the old pipeline (bearing or non-bearing),

- specific materials of thermoplastics planned to be used as dragged pipes (for example, polyethylene, polypropylene, etc., including their specific weights and SDR values of particular pipes);

- types of mortars to fill in the intertube space (including their specific weights);

- depth of the recovered pipelines and the water level above the pipeline to be restored;

- conditions of uniform and / or uneven filling with mortars of different specific gravity;

- degree of influence on the filling process of the presence and / or absence of water in the polymer pipeline.

\section{References}

1. Khramenkov SV, Primin OG, Orlov VA Reconstruction of pipeline systems (M. ASV. 2008) $215 \mathrm{p}$.

2. Santiago A., Durango M. (NO-DIG 2012, Sao Paulo, Brasil) [Report at the International Conference on Trenchless Technology, 2012, Sao Paulo, Brazil] 
3. Rehabilitation of gray gas lines by PE lining (6th International Pipeline Construction Symposium, Berlin, March 2009)

4. Mayr H. Entscheidungshilfen fur die Rehabilitation von Wasserrohrnetzen. (DVWG Hinweis Bonn, 2015) W 401 P 23

5. H.Sugawara. Some Economic Effects and Practices of Water Leakage Control in Japan. (AQUA, 2012), 5. p. 4-18

6. SP 31.13330.2012 Water supply. External networks and facilities, Updated version of SNiP 2.04.02-84* with the change No. 1

7. SP 32.13330.2012 "SNiP 2.04.03-85. Sewerage: External networks and structures" Actualized edition of SNiP 2.04.03-85

8. 32. SNiP 3.05.04-85 External networks and structures of water supply and sewerage

9. TTN 40-303-2003 Moscow (MGSN 6.01-03) Trenchless laying of communications with the use of microtunneling complexes and the reconstruction of pipelines with the use of special equipment. Adopted and put into effect by resolution of the Government of Moscow of August 3, (2004) No. 530-PP.

10. Instruction DWA-A 143-2 "Statistical calculations for the rehabilitation of sewage pipelines and channels using the" pipe in pipe "technology and using prefabricated elements. 132 pp. (2015)

11. Recommendations on the filling of the annular space for the rehabilitation of pipelines for relining methods and for laying pipelines in cases (TR 000 - 2013, Polyplastic Group, Moscow, 2013)

12. Recommendation DWA-A 143-2 Sanitation of external sewerage systems. Part 2. Static calculation of trenchless sanitation of sewer lines using the "pipe-to-pipe"

13. GOST 18599-2001 Polyethylene pressure pipes. Technical conditions 